Slavica

bruxellensia

\section{Slavica bruxellensia}

Revue polyphonique de littérature, culture et histoire

slaves

$1 \mid 2008$

Théâtre

\title{
Tutejšyja de Janka Kupala
}

La création de la nation biélorusse

\section{Ihar Skrypko}

Traducteur : Katia Vandenborre

\section{OpenEdition \\ Journals}

Édition électronique

URL : http://journals.openedition.org/slavica/78

DOI : 10.4000/slavica.78

ISSN : 2034-6395

Éditeur

Université libre de Bruxelles - ULB

Édition imprimée

Pagination : 65-67

ISSN : 2037-7654

\section{Référence électronique}

Ihar Skrypko, «Tutejšyja de Janka Kupala », Slavica bruxellensia [En ligne], 1 | 2008, mis en ligne le 15 octobre 2010, consulté le 21 avril 2019. URL : http://journals.openedition.org/slavica/78 ; DOI :

10.4000/slavica.78

Ce document a été généré automatiquement le 21 avril 2019

\section{(c) (i) $\odot$}

Les contenus de Slavica bruxellensia sont mis à disposition selon les termes de la Licence Creative Commons Attribution - Pas d'Utilisation Commerciale - Pas de Modification 3.0 France. 


\title{
Tutejšyja de Janka Kupala
}

\author{
La création de la nation biélorusse
}

\author{
Ihar Skrypko
}

Traduction : Katia Vandenborre

\section{NOTE DE L'ÉDITEUR}

La langue originelle de cet article est le russe.

1 La naissance d'une nation est toujours un processus complexe. Et il diffère pour chaque nation. Les uns s'aperçoivent un beau jour qu'ils forment une nation et considèrent cela tout simplement comme un fait établi. Pour les autres, ce processus fait l'effet d'une bombe : un tel scénario s'observe précisément quand la prise de conscience de la nation s'accorde avec sa création, les deux s'entremêlant et se nourrissant l'une de l'autre. Dans ce dernier cas de figure, il faut souligner le rôle prépondérant que jouèrent certaines personnalités ayant, toute leur vie durant, servi la nation qu'elles-mêmes avaient d'ailleurs fondée, mais aussi certaines œuvres qui soutinrent l'action de telles personnalités. Tel est le cas de Tutejšyja (Les gens d'ici) de Janka Kupala.

2 Janka Kupala, de son vrai nom Ivan Dominikovič Licevič, est un écrivain, poète et dramaturge biélorusse. Son pseudonyme est en soi très simple : «Janka » est la variante biélorusse de «Jean » et «Kupala » le nom d'une fête ancienne, célébrée le 6 juillet en l'honneur du solstice d'été. Janka Kupala est né le 7 juillet (donc le jour suivant la fête de Kupala) 1882 dans la propriété de Vjazynka, non loin de Minsk. La Biélorussie faisait alors partie de l'Empire russe, non pas en tant que Biélorussie (car officiellement sévissait une politique de non reconnaissance des Biélorusses comme peuple à part entière), mais en tant que "région du Nord-ouest ", unité administrative et territoriale dont le nom ne laissait entrevoir aucune particularité nationale légale. La culture biélorusse étant privée de toute diffusion de large amplitude, elle se développa presque exclusivement dans le sillage du folklore. C'est justement ce folklore qui inspira Kupala tout au long de son œuvre. 
3 Kupala écrivit et publia ses premiers vers en polonais. Il comprit cependant très vite qu'il ne pouvait véritablement s'exprimer que dans sa langue maternelle, le biélorusse. En 1905, il publia ses premiers poèmes en biélorusse.

Jusqu'en 1917, Kupala écrivit de nombreux vers, poèmes ainsi que ses premières pièces consacrées à la vie de la campagne et des paysans biélorusses. Aussi ses écrits continrentils de plus en plus d'appels au Biélorusse, compris non pas simplement comme un paysan (car, au XIX ${ }^{e}$ et au début du XX ${ }^{\mathrm{e}}$ siècles, les Biélorusses étaient principalement des paysans) ou un habitant de sa propre terre, mais surtout comme le membre d'une société nationale qui, au même titre que les autres peuples, a le droit de disposer d'elle-même. Ses œuvres devinrent de plus en plus populaires. Elles furent à la base de la formation de la langue littéraire biélorusse, dont l'usage, qui donnait la satisfaction de «se sentir Biélorusse ", est toujours d'actualité.

5 Sa poésie baigne dans un univers riche et féerique, habité par des créatures fantastiques telles que les domovyje (génies de la maison), les lešije (génies de la forêt), les rusalki (ondines) et les sorcières avec leurs frasques, leurs danses et leurs jeux. En cela, Kupala est un des principaux représentants $\mathrm{du}$ « romantisme national ». Cette tendance littéraire du début du XXe siècle soutenait alors le mouvement de renaissance nationale biélorusse.

6 En 1917, c'est avec enthousiasme que Kupala prit part à la révolution, encouragé par le mot d'ordre des communistes qui était le «droit des nations à l'autodétermination ». En effet, les premières années soviétiques favorisèrent largement le développement de la nation biélorusse. La République soviétique socialiste de Biélorussie fut créée, gagnant ainsi au sein de l'URSS une autonomie dont elle ne jouissait pas au sein de l'Empire russe. Des écoles, des instituts, des théâtres, etc. furent également ouverts. Néanmoins, le processus de renaissance nationale ne dura pas longtemps. Et bientôt il céda la place à une analyse critique de la réalité.

7 Ainsi, en 1922, de la plume de Kupala naquit la pièce Tutejšyja. Ce mot est utilisé en Biélorussie pour désigner un homme privé d'autodétermination nationale. Le principal conflit y oppose deux Biélorusses : l'un s'adapte à la situation, ne prêtant guère attention à son appartenance nationale, la changeant même au besoin ; l'autre se fait l'apologiste de l'édification nationale biélorusse. La pièce reflète en gros les deux variantes du scénario culturel biélorusse. La première est le produit des nombreux siècles d'appartenance à différents États: l'adaptation qu'elle propose peut se faire au prix du rejet de ses particularités nationales, de sa langue, de sa culture. La deuxième représente une forme d'escapisme, prônant le refus de la réalité et la création de son propre monde imaginaire, même petit, dans lequel le Biélorusse a sa place. Pour Kupala, la deuxième était la seule voie possible. Il considérait (et l'exprimait dans la pièce) que travailler lentement, progressivement et systématiquement à la formation de la culture biélorusse ainsi que combler ces lacunes qui autrefois ne pouvaient l'être pour des raisons politiques constituaient de très importants maillons de la construction nationale. D'après lui, le pire était d'aspirer à réintégrer un empire quel qu'il soit puisque, dans un empire, les Biélorusses n'avaient pas d'avenir.

8 Même d'après les canons de l'époque, la pièce ne contenait rien d'antisoviétique. Pourtant, elle fut interdite tant à l'impression qu'à la représentation scénique. Elle appelait vivement l'autodétermination nationale biélorusse et traitait explicitement les Russes et les Polonais comme des colonisateurs : cela effraya les autorités soviétiques. La pièce ne fut présentée aux spectateurs biélorusses qu'en 1989. Mise en scène à Minsk dans 
le théâtre «Janka Kupala », elle provoqua de vives réactions au sein du public (et pas seulement auprès de celui-ci). La situation des années 1920 et celle des années 1990 se révélèrent d'une ressemblance frappante. Le spectacle mis en scène par Nikolaj Pinigin ne quitta pas la scène pendant plus de quinze ans. Malheureusement, il y a quelques années, elle fut rayée du répertoire, et ce pour des raisons inconnues.

Peut-être sont-ce les poursuites engagées par les autorités en 1921 qui ont motivé Kupala à écrire sa pièce. En 1922, lors de la publication de la pièce, Kupala fut déclaré chauvin et antisoviétique. Ainsi, la presse se mit à le persécuter et, fin des années 1920, il fut soupçonné d'implication dans une organisation terroriste qui n'existait pas. En 1930, ne supportant plus les interrogatoires, il fit une tentative de suicide. Cette tentative fut un échec. Après cela, Kupala se sentit complètement abattu. À l'hôpital, il signa une lettre ouverte affirmant qu'il renonçait à toute idée nationale. Par la suite, il écrivit de pâles œuvres de propagande glorifiant l'Union soviétique, le parti communiste et Staline en personne. Malgré cela, en 1937 il se trouva à nouveau sur une liste de personnes devant être arrêtées. Seule la protection de personnalités haut placées dans le pays lui permit d'échapper au NKVD.

En 1942, Janka Kupala tomba dans les escaliers de l'hôtel « Moskva » à Moscou et se blessa à mort. Jusqu'à nos jours, nul ne sait s'il s'agissait d'un accident, d'un suicide ou d'un meurtre...

\section{INDEX}

Index chronologique : communisme, entre-deux-guerres, XXe siècle

Index géographique : Biélorussie

Mots-clés : littérature biélorusse, théâtre biélorusse

\section{AUTEURS}

\section{IHAR SKRYPKO}

Diplômé de master en Sciences humaines, dramaturge principal du Théâtre national du drame biélorusse à Minsk 